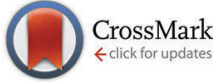

Cite this: Phys. Chem. Chem. Phys., $2015,17,23438$

\section{Electrochemical electron paramagnetic resonance utilizing loop gap resonators and micro- electrochemical cells $\dagger$}

\begin{abstract}
Mika A. Tamski, ${ }^{a}$ Julie V. Macpherson, ${ }^{b}$ Patrick R. Unwin ${ }^{b}$ and Mark E. Newton ${ }^{a}$
A miniaturised electrochemical cell design for Electron Paramagnetic Resonance (EPR) studies is reported. The cell incorporates a Loop Gap Resonator (LGR) for EPR investigation of electrochemically generated radicals in aqueous (and other large dielectric loss) samples and achieves accurate potential control for electrochemistry by using micro-wires as working electrodes. The electrochemical behaviour of the cell is analysed with COMSOL finite element models and the EPR sensitivity compared to a commercial $\mathrm{TE}_{011}$ cavity resonator using 4-hydroxy-2,2,6,6-tetramethylpiperidin-1-oxyl (TEMPOL) as a reference. The electrochemical EPR performance is demonstrated using the reduction of methyl viologen as a redox probe in both water and acetonitrile. The data reported herein suggest that sub-micromolar concentrations of radical species can be detected in aqueous samples with accurate potential control, and that subtle solution processes coupled to electron transfer, such as comproportionation reactions, can be studied quantitatively using EPR.
\end{abstract}

Received 21st July 2015

Accepted 12th August 2015

DOI: $10.1039 / c 5 c p 04259 c$

www.rsc.org/pccp

\section{Introduction}

Electron Paramagnetic Resonance (EPR) is a spectroscopic technique that has been applied to electrochemical systems since the early work of Austen et al. ${ }^{1}$ and Maki and Geske. ${ }^{2}$ Due to its high sensitivity towards paramagnetic species, EPR can provide key information about radical species generated or consumed during electrode reactions. EPR thus complements electrochemical data by directly identifying radical species, confirming reaction mechanisms, and revealing more subtle interactions, for example, between the radical and its environment. ${ }^{3,4}$ As such, EPR has not only provided a wealth of information to electrochemists, but EPR spectroscopists have also found electrochemical generation to be a feasible option to standard chemical and optical generation of radical species. ${ }^{5,6}$

There have been a number of approaches to the electrochemical (EC) cell design for EC-EPR, as evident from several reviews. $^{7-10}$ Due to significant dielectric losses at microwave frequencies, aqueous EC-EPR has typically involved the use of flat cells in conjunction with cavity resonators where the sample is as far as possible confined away from the electric fields

\footnotetext{
${ }^{a}$ Department of Physics, University of Warwick, Gibbet Hill Road, Coventry, CV4 7AL, UK.E-mail: m.e.newton@warwick.ac.uk

${ }^{b}$ Department of Chemistry, University of Warwick, Gibbet Hill Road, Coventry, CV4 $7 A L, U K$

$\dagger$ Electronic supplementary information (ESI) available: Fig. S1: The EC-EPR setup. See DOI: 10.1039/c5cp04259c
}

in the resonator. ${ }^{11-16}$ Electrochemical problems associated with these designs include significant ohmic-drop and large capacitive currents limiting the cell time constant. ${ }^{17,18}$ Problems in terms of EPR performance can include the deterioration of the resonator Quality factor ( $Q$-value) and hence EPR sensitivity due to the interaction of the microwave electric field with the metal electrodes and aqueous sample inside the resonator, ${ }^{7}$ reproducible alignment of the electrochemical cell inside the resonator between experimental runs, and the inhomogeneity of the microwave magnetic field $\left(B_{1}\right)$ inside a cavity resonator. ${ }^{19}$ Flat cells may also be prone to convection during prolonged electrolysis times ${ }^{6}$ leading to distortion of both the electrochemical and EPR performance.

Loop Gap Resonators (LGRs) were developed in the early 80's for EPR purposes ${ }^{20}$ and were applied to EC-EPR by Allendoerfer et al. ${ }^{21}$ allowing aqueous samples to be investigated with 50 to 100 times larger absolute sensitivities compared to other resonator-EC cell combinations at the time. In a LGR, the microwave electric field is mostly confined in the gaps of the resonator, allowing aqueous or other dielectrically "lossy" samples to occupy a larger volume relative to the size of the resonator. In addition to favourable EPR performance in aqueous systems for very small sample volumes ${ }^{22}$ (order of microliters), the smaller size of the resonator also allows the optimization of the electrochemical performance through miniaturization.

Ultramicroelectrode (UME) concepts have gone practically unnoticed in EC-EPR, although some examples of the use of small diameter wires exist. ${ }^{23-25}$ Electrochemically, the benefits 
of UMEs include diminished ohmic drop, shorter cell time constants and enhanced mass transport. ${ }^{26-28}$ However, for EC-EPR applications the small currents associated with UMEs can introduce significant challenges, as radical concentrations generated may be insufficient to allow the EPR study of shortlived intermediates or products. Among UMEs, the microcylindrical geometry is one of the simplest and easiest to fabricate and use and is particularly attractive in EC-EPR, as the length of the cylinder can be varied in order to produce the desired amount of current and thus generate a sufficient number of radicals in situ. ${ }^{29-31}$

Building on the early work of Allendoerfer et al. ${ }^{21}$ in this paper we report a new EC-EPR cell design that can be used with an X-band (8-12 GHz) LGR and water as a solvent. The use of micro-wire electrodes overcomes the electrochemical problems associated with flat cells, while the high sensitivity of the LGR makes the study of radical species possible, even with low currents. The design allows a range of working-, referenceand counter electrode (WE/RE/CE) materials and geometries to be used. Possible fouling of the WE can be addressed by exchanging the electrode without dissembling the entire cell and cell parts are reusable and interchangeable to allow maximum experimental flexibility.

\section{Experimental}

\section{Cell design}

A schematic of the cell designed for the EC-generation of radicals in situ within a LGR is shown in Fig. 1a. Parts 1, 3, 4 and 5 were machined from polyether ether ketone (PEEK) due to the mechanical and chemical stability of the material. Parts 1 and 3 support EPR test tubes, 2a: Q-band EPR tube $1.1 \mathrm{~mm}$
ID \& $1.6 \mathrm{~mm}$ OD, 2b: X-band EPR tube $3.0 \mathrm{~mm}$ ID \& $4.0 \mathrm{~mm}$ OD. $2 \mathrm{a}$ is the sample tube holding the solvent and therefore the ID determines the sample volume inside the resonator, but also contains the WE and RE. In an assembled set-up (Fig. 1b and Fig. S1, ESI $\dagger$ ) the inner tube holds the solvent away from the fringing electric fields of the LGR gaps. Thus, if necessary, the ID of $2 \mathrm{a}$ can be adjusted by choosing a suitable capillary and the performance of the setup optimised for solvents with different dielectric constants. To date, cells with ID's (2a) between 0.8 and $1.1 \mathrm{~mm}$ have been fabricated. The X-band tube (2b) acts as a structural support, making the assembled cell robust and easy to handle, while enabling symmetrical placement of the cell into the resonator.

Screw threads (c) on part 3 allow the attachment of the cell into the resonator (Fig. 1b) and also the adjustment of the WE inside the resonator in the $Z$-direction for optimal performance. Part 4 fits to part 3, resulting in a small chamber between them where the CE is located. The four channels in part 4 allow the attachment of Teflon tubing for solvent flow, but also permit the connection of the RE and CE to thicker wires outside the cell for electrical connection through part 5. This arrangement makes changing the RE and CE easy if necessary, whilst the additional channel enables mixing experiments to be conducted.

Part 6 is a fine capillary with dimensions of $c a .0 .15 \mathrm{~mm} \mathrm{ID,}$ $0.4 \mathrm{~mm}$ OD through which the WE is guided to the sensitive part of the LGR inside $2 \mathrm{a}$. The capillary can be removed and inserted back through part 4, allowing the WE to be changed when necessary. The bracketed part, from where the enlarged diagram is taken, represents the sensitive region of the 5-loop 4-gap LGR used in this work and has a length of $10 \mathrm{~mm}$ in the $Z$-direction. The RE, inserted into the cell through one of the pegs (5) is placed as close as possible to the WE to minimise the uncompensated resistance. The $\mathrm{CE}$ in the chamber of
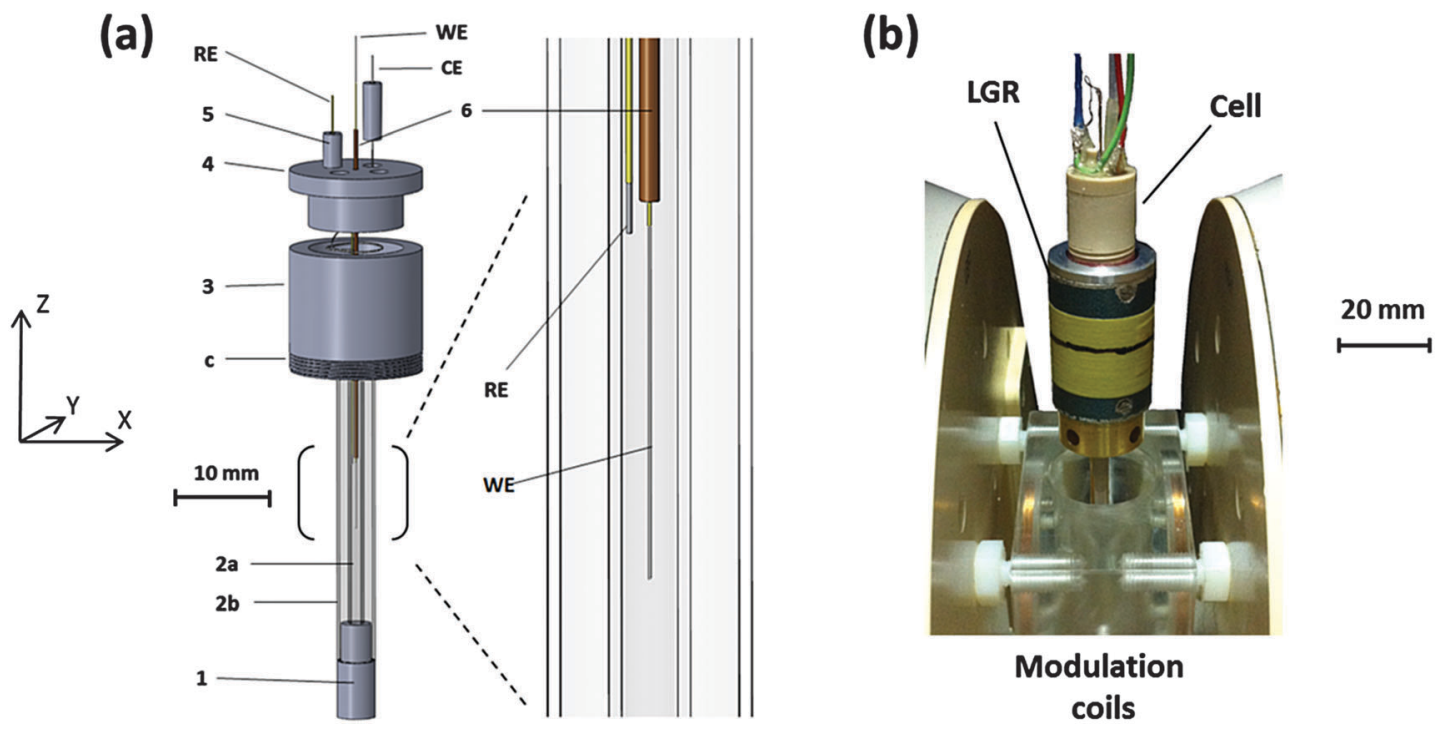

Fig. 1 (a) The EC-EPR cell designed for a LGR. 1 \& 3: capillary supports, 3c: threads to attach the cell to the resonator, 2a: Q-band EPR tube for the sample, 2b: standard X-band EPR tube for structural support, 4: adaptor for electrodes and sample flow, 5: pegs for electrode attachment, 6: capillary for inserting the working electrode (WE) to the sensitive part of the resonator, RE: reference electrode, CE: counter electrode. (b) Image of the cell attached to the resonator. For experiments the resonator is lowered inside the modulation coils. 
parts 3 and 4 is far enough from the active region of the resonator so that no interference from $\mathrm{CE}$ products is expected.

\section{Assembly}

An image of the cell attached to the LGR is shown in Fig. 1b, and the LGR, in turn, is attached to a coupling arm. For experiments, the setup is lowered to the middle of the modulation coils, which are fastened between the EPR magnet poles. The in-house built modulation coils provide the high frequency modulation of the DC magnetic field necessary for the lock-in detection in continuous wave (CW) EPR experiments. The LGR attaches to the coupling arm and is coupled to the microwaves inductively $^{32,33}$ through a rigid coaxial cable with a coupling loop at the end. The coupling arm enables the distance between the resonator and the loop to be adjusted so that a critical coupling can be achieved for optimum sensitivity.

The sample is deoxygenated in a glass syringe by bubbling $\mathrm{N}_{2}$ gas through it and introduced into the cell by a syringe pump (Legato 110) through PTFE tubing surrounded by a larger PVC tube. The interior of the PVC tubing is flushed with $\mathrm{N}_{2}$ during the experiment and the flow guided through the whole of the central cavity of the modulation coils, thus creating an inert atmosphere around the entire EC-EPR setup, enabling high reproducibility for oxygen free experiments. Fig. S1 (ESI $\dagger$ ) represents the setup in more detail.

\section{Materials}

Chemicals. Potassium chloride (BioXtra $\geq 99.0 \%$ ), potassium nitrate (ReagentPlus ${ }^{\circledR}, \geq 99.0 \%$ ), paraquat dichloride (Methyl Viologen; PESTANAL ${ }^{\mathbb{R}}$, analytical standard), tetrabutylammonium perchlorate (TBAP; Fluka, $\geq 99.0 \%$ ), hexammine ruthenium(III) chloride (98\%) and 4-hydroxy-TEMPO (TEMPOL; 97\%) were purchased from Sigma-Aldrich. Milli-Q water (Millipore Corp.) (resistivity $18.2 \mathrm{M} \Omega \mathrm{cm}, 25{ }^{\circ} \mathrm{C}$ ) was used for aqueous work and anhydrous acetonitrile (Sigma, 99.8\%) as an organic solvent. All chemicals were used as received. (Ferrocenylmethyl) trimethylammonium hexafluorophosphate $\left(\mathrm{FcTMA}^{+}\right)$was prepared as described elsewhere. ${ }^{34}$

Electrode wires. WEs were $50 \mu \mathrm{m}$ diameter Pt or Ag microwires coated with a $7.5 \mu$ m layer of polyester (Goodfellow, $\pm 10 \%$ tolerance in conductor diameter). The desired length of polyester (typically $7 \mathrm{~mm}$ ) was removed by soaking in saturated $\mathrm{KOH}$. CEs were bare $\mathrm{Pt}$ or $\mathrm{Ag}$ wires, and either bare or chloridized Ag wires of diameter $50 \mu \mathrm{m}$ or $125 \mu \mathrm{m}$ served as REs. Before commencing EC or EC-EPR experiments, the WE was cycled in the appropriate background electrolyte within the potential range for the mediator of interest, until a stable response was recorded. The potential was controlled through a potentiostat ( $\mathrm{CH}$ Instruments, $\mathrm{CHI} 1140 \mathrm{~B}$ ) in a three electrode configuration.

\section{Simulations}

The theory for the diffusion of electro-active species to a microcylindrical electrode has been developed for linear sweep experiments. Assuming uniformity along the cylinder, only a single dimension of diffusion has to be considered, and for a linear sweep the analytically obtained peak current density is: ${ }^{29}$

$$
j_{\mathrm{p}}=\frac{n^{2} F^{2} C^{*} a v}{R T}\left(\frac{0.446}{p}+\frac{0.335}{p^{1.85}}\right)
$$

where $n$ is the number of electrons transferred in the redox process, $F$ is the Faraday constant, $C^{*}$ is the bulk concentration of the electroactive species, $a$ is the radius of the cylinder, $v$ the scan rate, $R$ the universal gas constant and $T$ the temperature in Kelvin. $p$ is defined by:

$$
p=\sqrt{n F a^{2} v / T R D}
$$

where $D$ is the diffusion coefficient of the electroactive species. For high scan rates or large wire diameters the values of $p$ are also large, and the behaviour is dominated by linear diffusion, whereas for very slow scan rates or small electrode diameters $p$ is small and the behaviour approaches the steady state-solution characteristic of micro electrodes. $^{31}$

The WE placed inside a $0.8 \mathrm{~mm}$ ID sample tube (part 2a Fig. 1a) was modelled using COMSOL Multiphysics 4.4 (COMSOL AB) Finite Element Modelling (FEM) software. Fig. 2a shows a schematic representation of the model. The domain height and width are 11.2 and $0.4 \mathrm{~mm}$ respectively for the modelled $0.8 \mathrm{~mm}$ ID capillary in $2 \mathrm{D}$ axisymmetric geometry. Therefore, the model is not shown to scale, as the height of the domain is significantly greater than the width, but distinguishes the different types of boundaries used.

Boundary $1 \mathrm{a}$ is the wire electrode surface where the small edge $(1 \mathrm{~b})$ represents the tip of the wire. Boundary $2 \mathrm{a}$ is the wire insulation with $2 \mathrm{~b}$ representing the insulation edge $(7.5 \mu \mathrm{m})$ at the electrode/insulation interface. Boundary 3 represents the bulk solution in the capillary far away from the WE. Boundary 4 is the capillary wall where the concentration of the electroactive
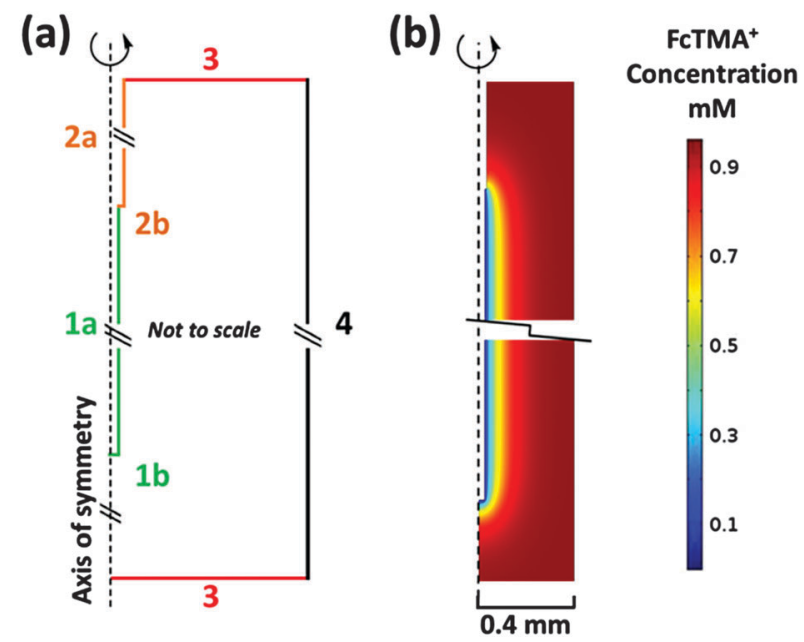

Fig. 2 2D axisymmetric COMSOL model. (a) Boundaries $1 \mathrm{a} \&$ b: WE, 2a 8 b: insulation, 3: bulk concentration, 4: capillary wall. (b) A snapshot of the concentration of FcTMA ${ }^{+}$within the cell during a $20 \mathrm{mV} \mathrm{s}^{-1}$ cyclic voltammogram between 0 and $0.6 \mathrm{~V}$ at the switching potential for oxidation of $1 \mathrm{mM} \mathrm{FcTMA}^{+}$at a $50 \mu \mathrm{m}$ diameter, $7 \mathrm{~mm}$ long, wire electrode. 
Table 1 Boundary conditions for the finite element model for $C V . C^{*}=$ $1.0 \mathrm{mM} \mathrm{FcTMA}^{+}, T=294 \mathrm{~K}, n=1, E_{0}=0.356 \mathrm{~V}, E_{\text {appl }}$ swept between 0.0 and $0.6 \mathrm{~V}$ linearly over time, $\mathrm{C}_{0, j}=\left[\mathrm{FcTMA}^{+}\right]$at the electrode surface as a function of the $E_{\mathrm{appl}}, F=96485 \mathrm{C} \mathrm{mol}^{-1}$ and $R=8.314 \mathrm{~J} \mathrm{~mol}^{-1} \mathrm{~K}^{-1}$

\begin{tabular}{|c|c|c|}
\hline Boundary & Boundary type & Boundary condition \\
\hline & & $C_{0, j}=\left(C^{*} \theta\right) /(1+\theta)$ \\
\hline $1 \mathrm{a}$ & Wire electrode & $\lceil(n F)$ \\
\hline $1 \mathrm{~b}$ & Electrode tip & $\theta=\exp \left[\left(\frac{n F}{R T}\right)\left(E_{0}-E_{\text {appl }}\right)\right.$ \\
\hline $2 \mathrm{a}$ & Wire insulation & $n \cdot \nabla C=0$ \\
\hline $2 \mathrm{~b}$ & Insulation edge & $n \cdot \nabla C=0$ \\
\hline 3 & Bulk solution & $C=C^{*}$ \\
\hline 4 & Capillary wall & $n \cdot \nabla C=0$ \\
\hline Axial symmetry & & $n \cdot \nabla C=0$ \\
\hline
\end{tabular}

species goes to zero. Corresponding boundary conditions for the model are summarised in Table 1.

For 100 and $20 \mathrm{mV} \mathrm{s}^{-1}$ scan rates simulated, 20000 and 15000 mesh points were applied respectively along the $7 \mathrm{~mm}$ long wire electrode (boundary 1a) and 25 mesh points to the electrode tip (boundary 1b). The domain was then meshed continuously with a maximum element growth rate of 1.02 from the electrode surface.

$\mathrm{FcTMA}^{+}$oxidation and the subsequent reduction of FcTMA ${ }^{2+}$ under diffusion control was modelled for cyclic voltammetry (CV) by solving Fick's second law for the concentration $(C)$ of reactant species:

$$
\frac{\partial C}{\partial t}=D_{j} \nabla^{2} C
$$

where $t$ is time and $\nabla^{2}$ is the Laplacian operator. The $D$ of $6.7 \times$ $10^{-6} \mathrm{~cm}^{2} \mathrm{~s}^{-1}$ and the formal potential $\left(E_{0}\right)$ of $0.356 \mathrm{~V}$ were determined using a $12.5 \mu \mathrm{m}$ diameter disc UME in a bulk solution of $1 \mathrm{mM} \mathrm{FcTMA}^{+}$in $0.4 \mathrm{M} \mathrm{KCl}$ against a $\mathrm{Ag} \mid \mathrm{AgCl}$ reference. Nernstian behaviour during $\mathrm{CV}$ was modelled at boundaries $1 \mathrm{a} \& \mathrm{~b}$, where the concentration of $\mathrm{FcTMA}^{+}\left(C_{0, j}\right)$ relative to FcTMA $^{2+}$ was controlled by sweeping the applied potential $\left(E_{\text {appl }}\right)$ between 0 and $0.6 \mathrm{~V}$ linearly over time.

Fig. $2 \mathrm{~b}$ is a snapshot of the concentration of $\mathrm{FcTMA}^{+}$in the cell during a $20 \mathrm{mV} \mathrm{s}^{-1} \mathrm{CV}$ recorded between 0 and $0.6 \mathrm{~V}$ at the switching potential of $0.6 \mathrm{~V}$. The figure is zoomed to the electrode/insulation interface and to the wire tip and thus boundaries 3 where $C=C^{*}$ lie further away than suggested by the figure. A $0.8 \mathrm{~mm}$ ID sample tube (2a, Fig. 1a) was chosen for the model, as the simulations results were identical to those obtained with the wire electrode in a bulk solution, indicating that for a symmetrically placed WE, the cell wall does not hinder the diffusion field, and thus the model is representative of eqn (1) and (2).

\section{The LGR}

The role of the resonator is to concentrate the $B_{1}$ field in the sample and make the signal produced by the change in magnetic susceptibility at resonance as large as possible. Rather than trying to fit the experiment to general purpose cavity EPR resonators, LGR's provide the opportunity to adapt the resonator to the experiment. The CW EPR signal is proportional to the loaded resonator $Q$-value $\left(Q_{\mathrm{L}}\right)$ and the filling factor $(\eta):^{35}$

$$
S \propto Q_{\mathrm{L}} \eta
$$

For LGRs, $Q_{\mathrm{L}}$ (the ratio of the microwave energy stored in the resonator loaded with a sample to that dissipated per cycle when critically coupled to the microwave bridge) is, in general, lower than that for a traditional cavity resonator at the same frequency. Nonetheless, $\eta$ (proportional to the ratio of $B_{1}{ }^{2}$ integrated over the sample to $B_{1}{ }^{2}$ integrated over the entire resonator) can be many times large than that for a high $Q$ cavity, and the resulting $\eta Q_{\mathrm{L}}$ product is often equal to or greater than that for a cavity. Also the more efficient separation of the microwave electric and $B_{1}$ fields in a LGR results in smaller dielectric losses when a lossy solvent is employed in the resonator. ${ }^{36}$

The use of LGR is particularly advantageous for samples of limited volume such as the concentration of short lived radical species in the diffusion field during an electrochemical experiment, and in cases where the sample is non-saturable and large $B_{1}$ fields can be used. ${ }^{22}$ In addition, LGRs also allow the miniaturization of the electrochemical setup, enabling the beneficial use of microelectrodes.

\section{EPR}

A 5-loop 4-gap resonator was used for the EPR measurements. 4 gaps allow the increase in the diameter of the sample loop, thus facilitating the use of a standard $4 \mathrm{~mm}$ OD X-band EPR tube as a structural support. Bruker X-band continuous wave spectrometer (EMX-8/2.7) was used for the EPR measurements. Coupling to the microwave source (Bruker ER 041 X-band Microwave Bridge) was achieved using in-house built coupling arm and inductive coupling.

\section{Results and discussion}

\section{The effect of the sample tube (2a) ID towards the EPR performance}

The larger the ID of the sample tube, the closer the sample is to the fringing electric fields in the gaps of the LGR, leading to an increasing dielectric microwave loss. The unloaded $Q$-value $\left(Q_{\mathrm{u}}\right)$ of the 5-loop 4-gap resonator is approximately 1700 in accordance with the literature. ${ }^{22}$ For water the $1.1 \mathrm{~mm}$ ID sample tube gives a typical $Q_{\mathrm{L}}=500-600$ at around $9.57 \mathrm{GHz}$, one third of the $Q_{\mathrm{u}}$. If the cell is filled with acetonitrile, $Q_{\mathrm{L}} \approx 900$. A cell assembled with the $0.8 \mathrm{~mm}$ ID sample tube filled with water gives a $Q_{\mathrm{L}}=800-900$ at around $9.51 \mathrm{GHz}$ frequency. Crucially the insertion of a micro-cylinder WE to the resonator does not introduce a noticeable change in the $Q$-value or the microwave coupling.

Higher $Q$-values suggest higher sensitivity. However, eventually the diminishing ID of the capillary starts to hinder the electrochemical performance (see Fig. 4 and discussion) and a compromise between the two has to be made depending on the system under investigation. 
EPR sensitivity comparison between LGR and cylindrical resonator

The EPR performance between the LGR and a cylindrical $\mathrm{TE}_{011}$ resonator was compared by placing a $1.1 \mathrm{~mm}$ ID capillary filled with water containing $10 \mu \mathrm{M}$ of the stable radical TEMPOL as a reference concentrically through each resonator. The $\mathrm{TE}_{011}$ cavity coupled critically with a $Q$-value of 1500 , whereas the $Q_{\mathrm{u}}$ for this resonator was closer to 5000, suggesting that both resonators performed at approximately $1 / 3$ of their $Q_{\mathrm{u}}$. Using a microwave power sweep, saturation curves for both resonators were constructed. The optimal signal to noise ratio $(\mathrm{S}: \mathrm{N})$ achieved with both resonators was approximately 120:1 (Fig. 3), indicating that in terms of concentration sensitivity they perform equally. Note that the EPR spectrum for $\mathrm{TE}_{011}$ cavity is offset for clarity.

Although the two resonators performed similarly, taking into account sample volumes inside the resonators, in terms of absolute sensitivity the LGR performed 2-3 times better. In the future $\eta$ for the LGR could be further increased by reducing the sample loop diameter leading to further sensitivity gains.

\section{Electrochemistry}

Experimental electrochemical characterization of two cells, representing the largest and smallest ID sample tubes used in this study, i.e. cell A $(1.1 \mathrm{~mm})$ and cell $\mathrm{B}(0.8 \mathrm{~mm})$ are shown in Fig. $4 \mathrm{a}$ and $\mathrm{b}$. The working electrode was a $50 \mu \mathrm{m}$ diameter $\mathrm{Pt}$ wire, $7 \mathrm{~mm}$ in length, with $125 \mu \mathrm{m}$ diameter $\mathrm{Ag} \mid \mathrm{AgCl} \mathrm{RE}$ and a bare Pt wire as a $\mathrm{CE}$, while $0.4 \mathrm{M} \mathrm{KCl}$ acted as a supporting electrolyte. The results of the COMSOL simulation (identical for cells A and B) of the CV for the FcTMA ${ }^{+/ 2+}$ are also shown in Fig. $4 \mathrm{a}$ and $\mathrm{b}$.

Fig. 4a reveals that at scan rate of $100 \mathrm{mV} \mathrm{s}^{-1}$ the EC CV behaviour for the oxidation of $1 \mathrm{mM} \mathrm{FcTMA}^{+}$is very close to that predicted by the simulation assuming a reversible diffusioncontrolled process. A peak to peak separation $\left(\Delta E_{\mathrm{P}}\right)$ value of 78 $\mathrm{mV}$ is predicted from the simulation, which shows that diffusion is not purely linear at the micro-cylinder electrode. For cell A the simulated $\Delta E_{\mathrm{p}}$ value is in good agreement with that recorded

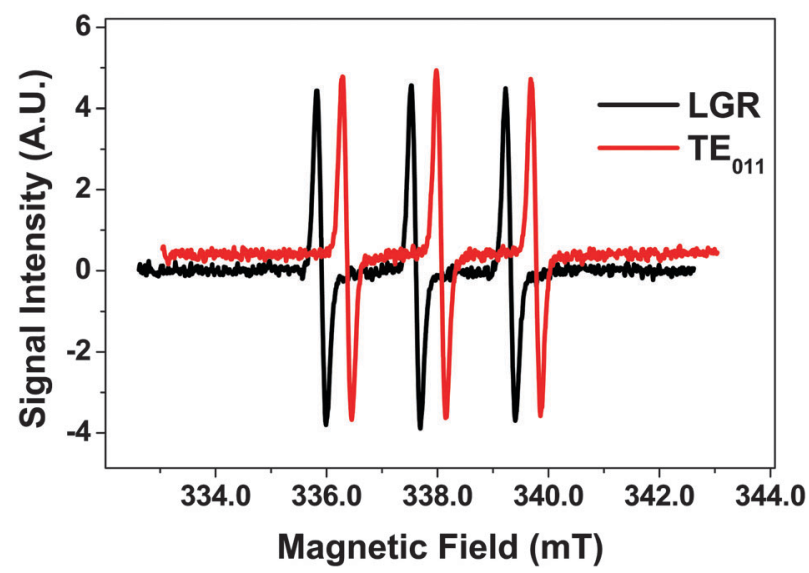

Fig. 3 1st derivative EPR spectra for $10 \mu \mathrm{M}$ TEMPOL in LGR and TE $E_{011}$ with $\mathrm{S}: \mathrm{N}=120$. Spectrum for $\mathrm{TE}_{011}$ is offset for clarity by $0.45 \mathrm{mT}$ and $0.4 \mathrm{SI}$ units.
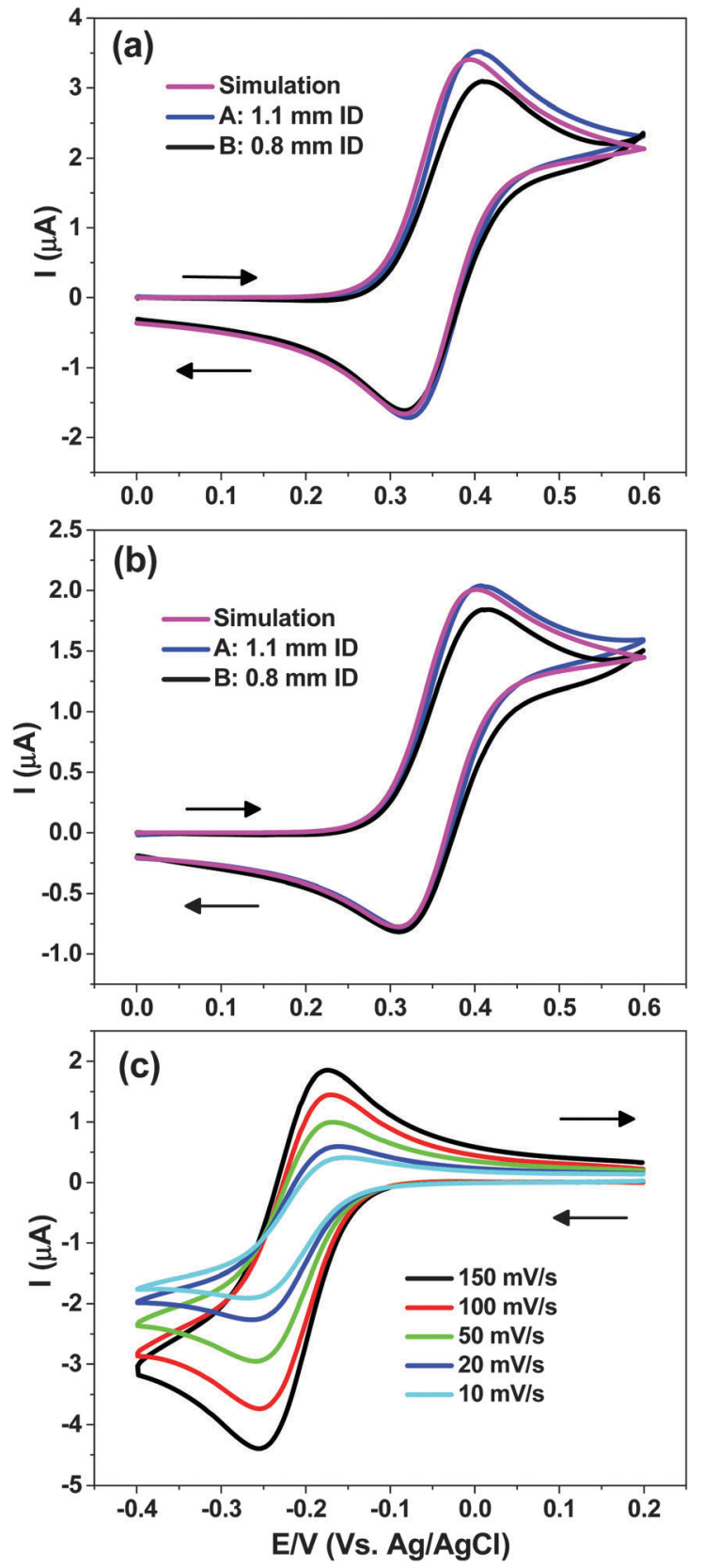

Fig. 4 Electrochemical characterization of cells $A(1.1 \mathrm{~mm} \mathrm{ID)}$ and $B$ $(0.8 \mathrm{~mm}$ ID) in water and comparisons with simulations. (a) $1.0 \mathrm{mM}$ FCTMA $^{+}$; CV at $100 \mathrm{mV} \mathrm{s}^{-1}$, (b) $1.0 \mathrm{mM} \mathrm{FCTMA}^{+}$; CV at $20 \mathrm{mV} \mathrm{s}^{-1}$, (c) $1.0 \mathrm{mM} \mathrm{Ru}\left(\mathrm{NH}_{3}\right)_{6}{ }^{3+}$ at different scan rates. All results recorded at $\mathrm{Pt}$ wire electrode $50 \mu \mathrm{m}$ in diameter, $7 \mathrm{~mm}$ length vs. $\mathrm{Ag} \mid \mathrm{AgCl}$ reference and $0.4 \mathrm{M} \mathrm{KCl}$ as a supporting electrolyte.

experimentally, i.e. $83 \pm 2 \mathrm{mV}$. Note that increasing the supporting electrolyte concentration was observed to decrease the $\Delta E_{\mathrm{P}}$ (due to Ohmic drop effects in the cell geometry employed) until values of $c a$. $0.4 \mathrm{M}$, beyond which increasing the concentration showed no appreciable effect. For the cell B measured $\Delta E_{\mathrm{P}}$ value was $94 \pm 2 \mathrm{mV}$, the difference to that obtained for cell $\mathrm{A}$ essentially due to a stretched out oxidative wave of the CV.

Fig. $4 \mathrm{~b}$ shows the behaviour at $20 \mathrm{mV} \mathrm{s}^{-1}$ scan rate, where increased radial diffusion effects will contribute. This is reflected 
in a larger simulated $\Delta E_{\mathrm{P}}=93 \mathrm{mV}$ which compares favourably with $94 \pm 2 \mathrm{mV}$ measured for cell A. For cell B the measured $\Delta E_{\mathrm{P}}$ of $104 \pm 2 \mathrm{mV}$ suggests that at slower scan rates this cell behaviour is closer to that predicted.

For cell $\mathrm{A}$, the experimental peak current $\left(i_{\mathrm{P}}\right)$ was within $3 \%$ of that simulated irrespective of the scan rate whereas for cell $\mathrm{B}$ the $i_{\mathrm{P}}$ value was consistently $8 \%$ lower. As discussed above in the simulations section, the capillary wall is not expected to hinder the diffusion field for $0.8 \mathrm{~mm}$ ID sample tube. A possible explanation for the slightly lower $i_{\mathrm{P}}$ and larger $\Delta E_{\mathrm{P}}$ values is the fact that the WE is not completely symmetrically placed within the capillary. Thus the diffusion field might be restricted by the capillary wall, although the observed $i_{\mathrm{P}}$ values for cell $\mathrm{B}$ are still within the tolerance of the wire diameter $( \pm 10 \%)$ reported by the manufacturer.

The simulated $i_{\mathrm{P}}$ for the oxidation wave at $20 \mathrm{mV} \mathrm{s}^{-1}$ agreed with that predicted analytically (eqn (1) and (2)) to within $0.5 \%$, and for $100 \mathrm{mV} \mathrm{s}^{-1}$ to within $2 \%$. For the latter scan rate the no. of mesh points required to approach the value predicted by the analytical equations started to increase exponentially for an incremental increase in simulated $i_{\mathrm{P}}$.

Fig. 4c shows reduction of $\mathrm{Ru}\left(\mathrm{NH}_{3}\right)_{6}{ }^{3+/ 2+}$ for the cell $\mathrm{A}$ at different scan rates. The gradual change in the shape of the $\mathrm{CV}$ is evident as the measured $\Delta E_{\mathrm{P}}$ increases from 80 to $114 \mathrm{mV}$ as the scan rate is reduced from 150 to $10 \mathrm{mV} \mathrm{s}^{-1}$. For mediators such as $\mathrm{Ru}\left(\mathrm{NH}_{3}\right)_{6}{ }^{3+/ 2+}$ and $\mathrm{FcTMA}^{+/ 2+}$, scan rates between 10 and $150 \mathrm{mV} \mathrm{s}^{-1}$ seem to be practical for the cell described.

\section{Electrochemical EPR}

EPR was carried out in the presence of the electrochemical redox mediator methyl viologen $\left(\mathrm{MV}^{2+}\right)$ which undergoes two consecutive one electron reduction steps, the first being:

$$
\mathrm{MV}^{2+}+\mathrm{e}^{-} \leftrightharpoons \mathrm{MV}^{+} \bullet
$$

where the paramagnetic species $\mathrm{MV}^{+} \bullet$ is formed. Previous work has shown this species to be sufficiently stable for convenient detection in EC-EPR. ${ }^{16,37}$ A typical CV for the reduction of $1 \mathrm{mM}$
$\mathrm{MV}^{2+}$ in water and $0.4 \mathrm{M} \mathrm{KNO}_{3}$ at a $\mathrm{Ag}$ wire electrode $(50 \mu \mathrm{m}$ diameter, $7 \mathrm{~mm}$ length) for cell $\mathrm{A}$ is shown in Fig. 5a. The structure of the $\mathrm{MV}^{2+}$ is displayed in the inset to Fig. 5a. The $\Delta E_{\mathrm{P}}$ value of $98 \mathrm{mV}$ for a $20 \mathrm{mV} \mathrm{s}^{-1}$ scan rate suggests essentially a reversible behaviour, as discussed for Fig. $4 \mathrm{~b}$ above and previously suggested by literature. ${ }^{38,39}$

From the $\mathrm{CV}$ in Fig. $5 \mathrm{a}$ a potential of $-0.9 \mathrm{~V}$ was chosen to generate $\mathrm{MV}^{+} \bullet$ under diffusion limited conditions. Fig. 5b shows the spectrum of the radical after electrolysing $1 \mathrm{mM}$ $\mathrm{MV}^{2+}$ solution in the cell A for 2 min. The EPR scan was initiated as the potential was switched off.

The EPR spectrum obtained with $0.02 \mathrm{mT}$ modulation, averaging 5 scans gave a signal to noise $(\mathrm{S}: \mathrm{N})$ of $740: 1$. The Root Mean Square (RMS) value for the noise was calculated from the baseline on a low field side of the spectrum. The emerging hyperfine coupling suggests that no line broadening occurs due to electron exchange between radical-parent interaction proposed previously: ${ }^{24}$

$$
\left(\mathrm{MV}^{+\bullet}\right)+\left(\mathrm{MV}^{2+}\right)^{*} \leftrightharpoons\left(\mathrm{MV}^{+\bullet}\right)^{*}+\left(\mathrm{MV}^{2+}\right)
$$

This is probably due to the relatively low concentration of the parent molecule with respect to the radical species in the active part of the resonator. In fact the best least squares fit yielded a line width of $0.017 \mathrm{mT}$ for the smallest hyperfine couplings, further suggesting that the lines were not excessively broadened by radical-radical or radical-parent molecular interactions. Under these conditions the line width would exceed the used modulation amplitude of $0.02 \mathrm{mT}$. The result in $5 \mathrm{~b}$ is in fact closer to those obtained for $\mathrm{MV}^{+\bullet}$ productions through chemical reduction ${ }^{40}$ or an exhaustive electrolysis of $1 \mathrm{mM} \mathrm{MV}^{2+}$ reported by Bard et al. ${ }^{16}$

A complementary option for scanning the magnetic field to record the entire EPR spectrum is to fix the field to a given value and monitor the signal amplitude as a potential perturbation is applied. This allows the generation of radical species at the electrode as a function of time and potential to be monitored simultaneously. Fig. 6 shows an average EPR signal amplitude
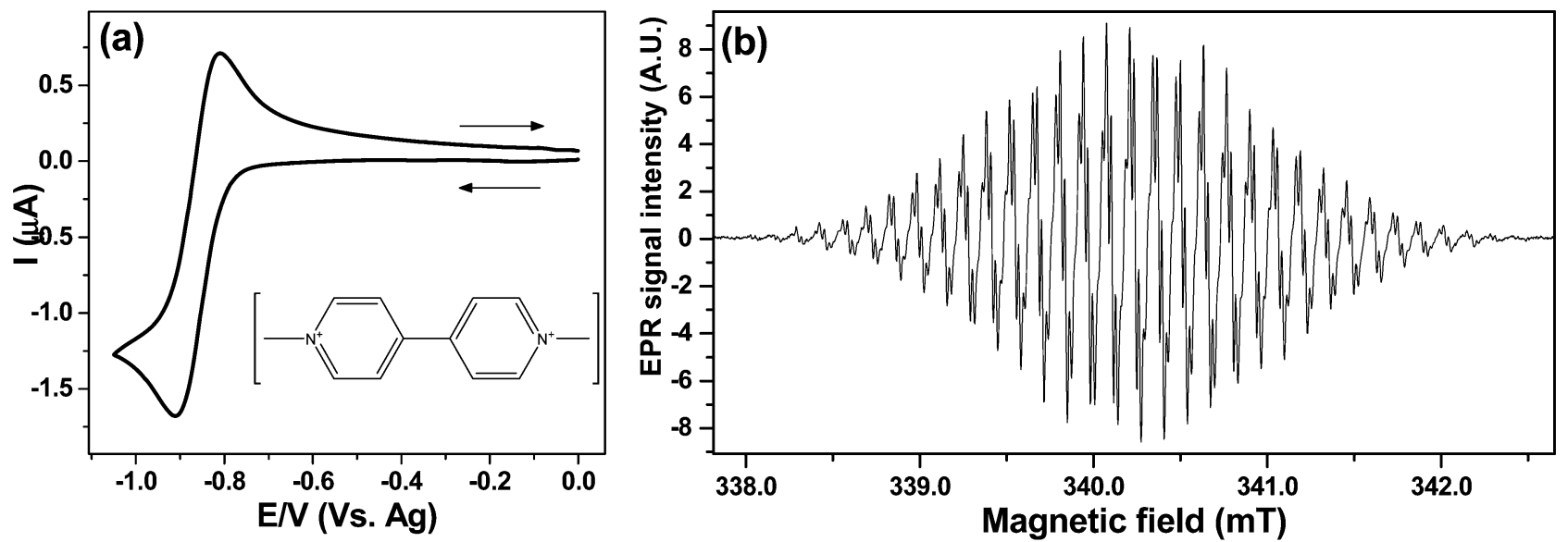

Fig. 5 EC-EPR in cell A: (a) CV at $20 \mathrm{mV} \mathrm{s}^{-1}$ for $1 \mathrm{mM} \mathrm{MV}^{2+}$ at a $50 \mu \mathrm{m} \mathrm{Ag}$ wire electrode $v$ s. a Ag-pseudo reference in water with $0.4 \mathrm{M} \mathrm{KNO}, \Delta E_{\mathrm{P}}=98 \mathrm{mV}$. Inset: The molecular structure of $\mathrm{MV}^{2+}$. (b) EPR spectrum of $\mathrm{MV}^{+} \bullet$ recorded after a 2 min potential step at $-0.9 \mathrm{~V}, 2 \mathrm{~mW}$ microwave power, $0.02 \mathrm{mT}$ modulation. 


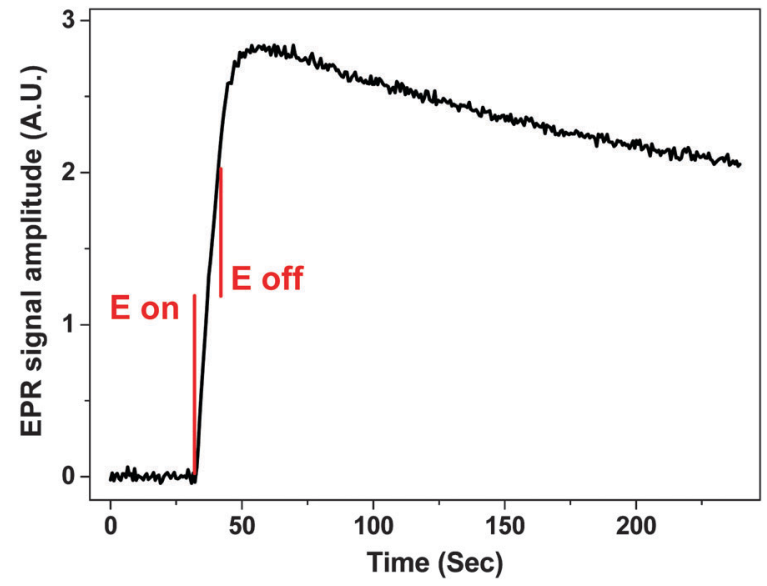

Fig. 65 scan average of the EPR signal amplitude at constant magnetic field as a function of potential and time during a 10 second potential step to $-1.0 \mathrm{~V}$ from $0 \mathrm{~V}$. $1 \mathrm{mM}$ of $\mathrm{MV}^{2+}$ in water at $50 \mu \mathrm{M}$ diameter $\mathrm{Ag}$ wire electrode vs. Ag pseudo RE and $0.4 \mathrm{M} \mathrm{KNO}_{3}$ in the cell B. $\mathrm{S}: \mathrm{N}=122: 1$ with $2 \mathrm{~mW}$ microwave power and $0.1 \mathrm{mT}$ modulation.

of 5 repetitions as a function of potential and time for $1 \mathrm{mM}$ $\mathrm{MV}^{2+}$ in water and $0.4 \mathrm{M} \mathrm{KNO}_{3}$, as the WE is stepped to $-1.0 \mathrm{~V}$ for 10 seconds in cell $B$. Between the 5 repetitions, fresh solution was inserted to the cell via a syringe pump.

The charge generated during a 10 second potential step was ca. $1.4 \times 10^{-5} \mathrm{C}$, indicating that the number of radical species $\left(\mathrm{MV}^{+} \bullet\right)$ generated was $8.7 \times 10^{13}$. The volume of sample inside the sensitive part of the resonator was $5 \mu \mathrm{L}$, and thus the concentration of the radical species can be estimated to ca. $30 \mu \mathrm{M}$, assuming $100 \%$ efficient electron transfer and that the radical decay is negligible during the relatively short potential step. The $\mathrm{S}: \mathrm{N}=122: 1$ when the signal was taken to be the maximum EPR amplitude, while for the noise a RMS was calculated from the region before the potential step. Extrapolating from the results in Fig. 6, the limit of quantification (LOQ) was estimated to be $7.1 \times 10^{12}$ and the limit of detection
(LOD) $2.1 \times 10^{12}$ spins or 2.4 and $0.7 \mu \mathrm{M}$, respectively if the experiment was to be repeated 5 times.

The increase in the EPR signal shown in Fig. 6 is rapid after the potential step is applied at 32 seconds into the experiment. The EPR signal intensity increases for $c a$. 10 seconds after the potential switches off at 42 seconds, which could be attributed to the radical diffusing away from the electrode surface introducing changes to the filling factor and to the distribution of the radical within the $B_{1}$ field inside the sample volume. Also the formation of an EPR silent radical cation dimer in water has been proposed ${ }^{41,42}$

$$
2 \mathrm{MV}^{+\bullet} \rightleftharpoons(\mathrm{MV})_{2}{ }^{2+}
$$

the presence of which could have an effect on the EPR signal at least on short timescales at the vicinity of the WE.

During the following 180 seconds after the potential was switched off the signal intensity decreased to $70 \%$ of the largest value, confirming the observation that $\mathrm{MV}^{+} \bullet$ is indeed a stable radical in aqueous systems at least around neutral pH. No decay constant was calculated, as with the current setup it is possible that the stable radical could diffuse out of the sensitive part of the resonator within 180 seconds.

A wider potential sweep CV between -0.2 and $-1.4 \mathrm{~V}$ for both reduction peaks of $\mathrm{MV}^{2+}$ is shown in Fig. 7a for cell B, corresponding to the electron transfer processes in eqn (5) and also eqn (8)

$$
\mathrm{MV}^{+\bullet}+\mathrm{e}^{-} \rightleftharpoons \mathrm{MV}^{0}
$$

where the paramagnetic one electron reduction product is further reduced to diamagnetic and EPR silent $\mathrm{MV}^{0}$ species. An increase in the EPR signal amplitude (right $y$-axis) was observed (1) as the reduction in eqn (5) started to produce the paramagnetic species at the WE (left $y$-axis), and did not cease until the peak current for the second reduction step (2).

After this point, the EPR signal remained constant while the switching potential was reached and the scan reversed,
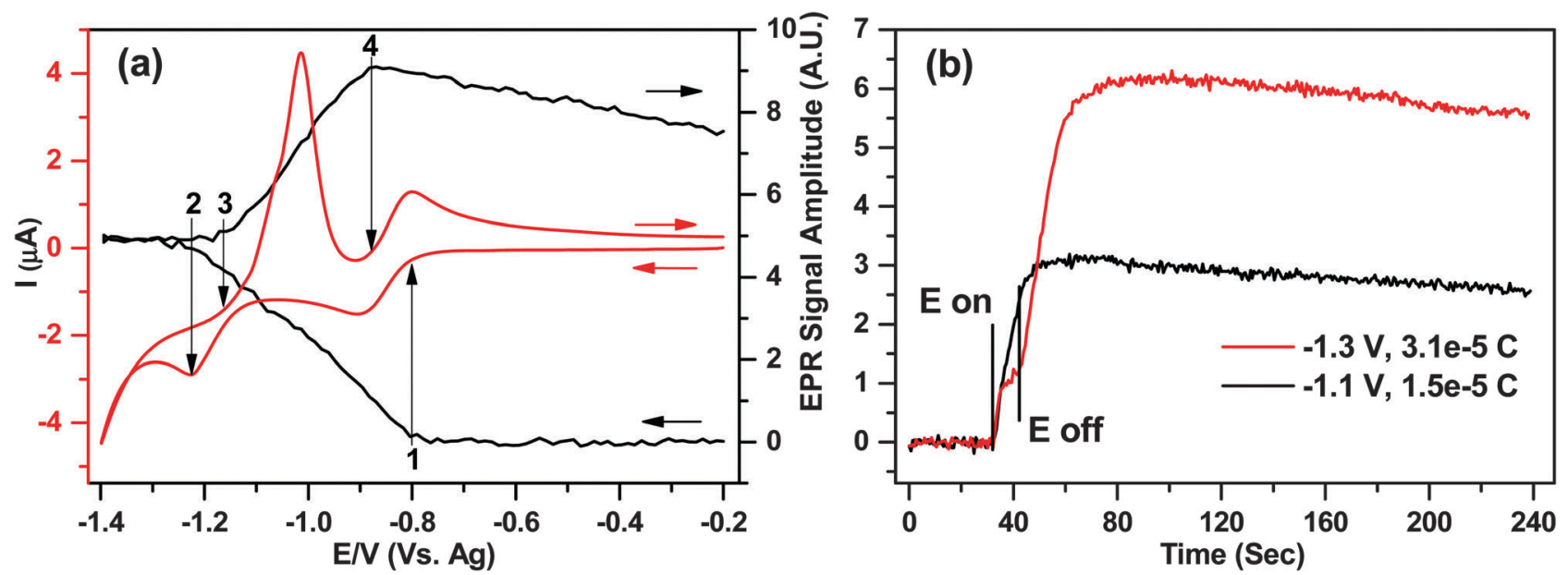

Fig. 7 (a) EPR signal amplitude (right $y$-axis) vs. redox processes for $1 \mathrm{mM} \mathrm{MV}{ }^{2+/ 1+\bullet / 0}$ (left $y$-axis) in water during $20 \mathrm{mV} \mathrm{s} \mathrm{s}^{-1} \mathrm{CV}_{\text {; }}$ (b) EPR signal intensity vs. time during 10 second potential steps from $-0.2 \mathrm{~V}$ to $-1.1 \mathrm{~V}$ and $-1.3 \mathrm{~V}$. Both (a) and (b) with $50 \mu \mathrm{m}$ diameter Ag wire electrode vs. Ag pseudo RE, $0.4 \mathrm{M}$ $\mathrm{KNO}_{3}$ in the cell B. $2 \mathrm{~mW}$ microwave power and $0.1 \mathrm{mT}$ modulation. 
indicating that a steady concentration of radical species was maintained in the cell for $c a .20$ seconds, at least on the EPR sensitivity scale. This result seems surprising as at high negative potentials the parent $\mathrm{MV}^{2+}$ molecule would be expected to reduce to $\mathrm{MV}^{0}$, while the already generated $\mathrm{MV}^{+} \bullet$ would also go through the second reduction step, thus leading to a diminishing EPR signal.

The EPR signal intensity started to increase again during the return scan at the onset of peak (3) on the voltammogram, where eqn (8) was reversed. The shape of the first oxidation peak during the reverse scan suggests a precipitation or deposition of the neutral $\mathrm{MV}^{0}$ on the surface, and subsequent stripping from the electrode. This was also supported by the EPR as the rate of EPR signal increase between points (3) and (4) was ca. 25\% larger than between (1) and (2), suggesting that the arrival of the species to the electrode surface exceeded the diffusion limit. Integration of the stripping peak yielded a charge of $2.5 \times 10^{-5} \mathrm{C}$ or $1.6 \times 10^{14}$ molecules being oxidized during the reversal of eqn (8).

Finally the EPR signal intensity started to decrease at the onset of the second oxidation peak of the return wave (4) where eqn (5) was reversed. The signal intensity diminished by less than $20 \%$, as the radical diffused throughout the sample volume and did not have time to arrive to the electrode for oxidation before the experiment finished.

The unexpected levelling of the EPR signal intensity at potentials beyond $c a .-1.2 \mathrm{~V}$ in Fig. 7a was further investigated by applying two independent 10 second potential steps at $-1.1 \mathrm{~V}$ and $-1.3 \mathrm{~V}$, corresponding to points just before and after the second reduction step, respectively. Fig. 7b displays the EPR amplitudes ( $y$-axis) as a function of time ( $x$-axis), and the applied potentials.

For the $-1.1 \mathrm{~V}$ potential step corresponding to the process in eqn (5) the EPR signal increased as expected based on the data in Fig. 6 and $c a .1 .5 \times 10^{-5} \mathrm{C}$ of charge was transferred. On the other hand, when the potential was stepped to $-1.3 \mathrm{~V}$, after the initial increase in the EPR signal a distinct plateau was observed, and the EPR signal increase didn't resume at the expected rate until the potential was switched off. None the less, as almost exactly twice the charge was generated during the step $\left(3.1 \times 10^{-5} \mathrm{C}\right)$ combined with exactly double the EPR signal, there is a clear quantitative evidence that the final product in the solution is the paramagnetic $\mathrm{MV}^{+}$. and not the neutral $\mathrm{MV}^{0}$ that the applied potential would suggest.

From Fig. 7a it was determined that $\mathrm{MV}^{0}$ is likely to deposit on the surface of the electrode, so the increase of the EPR signal after the potential is switched off at $-1.3 \mathrm{~V}$ can be attributed to a process in eqn (9), proposed by Monk et al. ${ }^{42}$

$$
\mathrm{MV}^{0}+\mathrm{MV}^{2+} \rightarrow 2 \mathrm{MV}^{+\bullet}
$$

although results reported therein did not display the quantitative behaviour described here. Due to an existing concentration gradient, $\mathbf{M V}^{2+}$ species still diffuses to the electrode surface after the potential step and can react with the $\mathrm{MV}^{0}$ thus yielding two paramagnetic molecules. As long as there is an applied
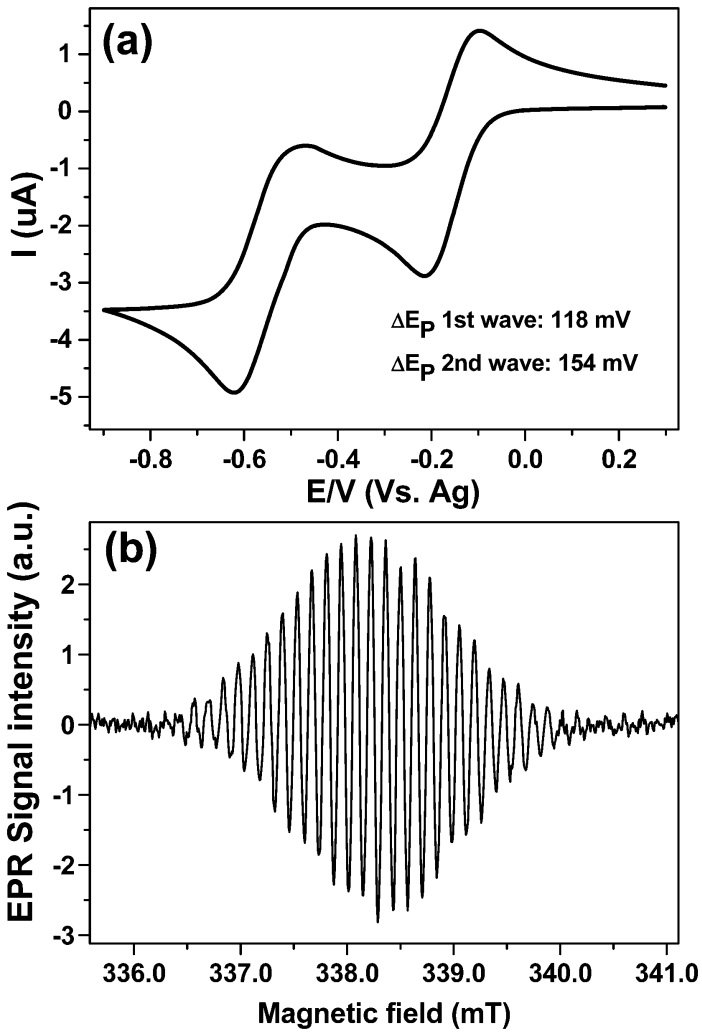

Fig. $81 \mathrm{mM} \mathrm{MV}{ }^{2+}, 0.2 \mathrm{M}$ TBAP in anhydrous acetonitrile at a $50 \mu \mathrm{m}$ diameter Pt wire electrode vs. Ag-pseudo reference (a) $100 \mathrm{mV} \mathrm{s}^{-1} \mathrm{CV}$, (b) EPR spectrum of $\mathrm{MV}^{+\bullet}$ in cell A, $2 \mathrm{~mW}$ microwave power, $0.05 \mathrm{mT}$ modulation and $42 \mathrm{~s}$ scan time.

potential the paramagnetic product from eqn (9) is further reduced to the diamagnetic form and a plateau in the EPR signal intensity is observed.

Clearly this setup allows the characterization of electrode processes under precise potential control on a quantitative level with high EPR sensitivity. In the future EC-EPR could be used for example to study comproportionation reactions, previously performed on UMEs, on equal or even lower redox mediator concentrations than before. ${ }^{43}$

Finally cell A was tested using a solvent with a moderate dielectric loss, acetonitrile. Fig. 8a displays the CV obtained at $100 \mathrm{mV} \mathrm{s}^{-1}$ scan rate over the both reduction steps for $1 \mathrm{mM}$ $\mathrm{MV}^{2+}$ at a $50 \mu \mathrm{m}$ diameter platinum WE $v s$. Ag-pseudo reference using $0.2 \mathrm{M}$ TBAP as a supporting electrolyte. Clearly in acetonitrile the neutral $\mathrm{MV}^{0}$ does not deposit on the electrode nor precipitate out of solution, at least to any significant extent, as both peaks of the return wave have a symmetry indicative of mass transport limitation, when compared to the CV in Fig. 7a. The larger cell resistance is obvious from the stretched $\Delta E_{\mathrm{p}}$ value for the first wave $(118 \mathrm{mV})$ when compared to the aqueous results.

The high EPR sensitivity is evident from Fig. 8b which was obtained after stepping the potential to $-0.3 \mathrm{~V}$ with a single EPR scan for a concentration of $c a .20 \mu \mathrm{M}$ of $\mathrm{MV}^{+} \bullet$ giving $\mathrm{S}: \mathrm{N}$ of $72: 1$ for 42 sec scan time, indicating that EC-ERP measurements are possible also with organic solvents. 


\section{Conclusions}

A novel design of EC-EPR cell has been presented and its electrochemical performance demonstrated with well-known redox mediators. The electrochemical EPR performance was analysed by characterising the behaviour of $\mathrm{MV}^{2+}$ in an aqueous system. These results suggest that the potential control of the cell is precise enough for analytical experiments, while the simultaneous EPR behaviour of the system can be monitored quantitatively under inert atmosphere.

Silver, gold and platinum can be used as a WE material between 25 and $125 \mu \mathrm{m}$ conductor diameters. Also a piece of mesh has been inserted to the capillary instead of a wire and successful EC-EPR experiments performed, although at the expense of the potential control.

In terms of EPR sensitivity the LGR turned out to perform as well as commercially available cylindrical $\mathrm{TE}_{011}$ resonator. Sub $\mu \mathrm{M}$ EPR limits of detection have been demonstrated even for radicals such as $\mathrm{MV}^{+} \bullet$ with complicated multi-line EPR spectra. Much lower detection limits are of course possible for radicals with simple single line EPR spectra. The sensitivity of the LGR allows the use of relatively small surface area micro wires and also a true miniaturization of the electrochemical cell. As the syringe pump/potentiostat/EPR interface can be programmed and thus certain experiments automated, signal averaging can be efficiently used to study short liver radicals.

Although designed primarily for aqueous samples, the applicability for organic solvents has also been demonstrated.

Obviously there are several parameters to optimise in EC-EPR, depending on the system under study. The design demonstrated here allows the maximum flexibility between the electrochemistry and EPR. Further work is underway for a detailed characterization of the setup for the routine absolute quantification of paramagnetic species in EC-EPR experiments.

\section{Acknowledgements}

The author would like to thank the EPSRC National EPR Research Facility \& Service, Manchester for training in EC-EPR and the EPSRC Integrated Magnetic Resonance Centre for Doctoral Training (EP/J500045/1).

\section{References}

1 D. E. G. Austen, P. H. Given, D. J. E. Ingram and M. E. Peover, Nature, 1958, 182, 1784-1786.

2 A. H. Maki and D. H. Geske, J. Chem. Phys., 1959, 30, 1356-1357.

3 A. J. Bard and L. R. Faulkner, Electrochemical Methods: Fundamentals and Applications, John Wiley \& Sons, Inc., 2nd edn, 2001.

4 L. Dunsch, J. Solid State Electrochem., 2011, 15, 1631-1646. 5 P. H. Rieger, I. Bernal, W. H. Reinmuth and G. K. Fraenkel, J. Am. Chem. Soc., 1963, 85, 683-693.

6 L. H. Piette, P. Ludwig and R. N. Adams, Anal. Chem., 1962, 34, 916-921.
7 R. N. Bagchi, A. M. Bond and F. Scholz, Electroanalysis, 1989, 1, 1-11.

8 A. M. Waller and R. G. Compton, in Comprehensive Chemical Kinetics, ed. R. G. Compton, Elsevier, 1989, vol. 29, pp. 297-352.

9 J. D. Wadhawan and R. G. Compton, in Encyclopedia of Electrochemistry, ed. A. J. Bard, M. Stratmann and E. J. Calvo, WileyVCH Verlag GmbH \& Co. KGaA, 2003, vol. 29, pp. 170-220.

10 P. R. Murray and L. J. Yellowlees, Spectroelectrochemistry, The Royal Society of Chemistry, 2008, pp. 207-231.

11 B. A. Coles and R. G. Compton, J. Electroanal. Chem., 1983, 144, 87-98.

12 R. G. Compton, P. J. Daly, P. R. Unwin and A. M. Waller, J. Electroanal. Chem., 1985, 191, 15-29.

13 H. Park, M. S. Won, C. Cheong and Y. B. Shim, Electroanalysis, 2002, 14, 1501-1507.

14 A. Petr, L. Dunsch and A. Neudeck, J. Electroanal. Chem., 1996, 412, 153-158.

15 E. Dmitrieva, Y. Harima and L. Dunsch, J. Phys. Chem. B, 2009, 113, 16131-16141.

16 J. G. Gaudiello, P. K. Ghosh and A. J. Bard, J. Am. Chem. Soc., 1985, 107, 3027-3032.

17 I. B. Goldberg, A. J. Bard and S. W. Feldberg, J. Phys. Chem., 1972, 76, 2550-2559.

18 I. B. Goldberg and T. M. McKinney, in Laboratory techniques in electroanalytical chemistry, ed. P. T. Kissinger and W. R. Heineman, Dekker, New York, 1984, pp. 675-728.

19 R. N. Adams, J. Electroanal. Chem., 1964, 8, 151-162.

20 W. Froncisz and J. S. Hyde, J. Magn. Reson., 1982, 47, 515-521.

21 R. D. Allendoerfer, W. Froncisz, C. C. Felix and J. S. Hyde, J. Magn. Reson., 1988, 76, 100-105.

22 J. S. Hyde and W. Froncisz, in Advanced EPR: applications in biology and biochemistry, ed. A. J. Hoff, Elsevier, 1989, pp. 1-29.

23 R. N. Bagchi, A. M. Bond and R. Colton, J. Electroanal. Chem., 1986, 199, 297-309.

24 R. N. Bagchi, A. M. Bond and F. Scholz, J. Electroanal. Chem., 1988, 252, 259-267.

25 D. A. Fiedler, M. Koppenol and A. M. Bond, J. Electrochem. Soc., 1995, 142, 862-867.

26 M. Fleischmann and S. Pons, J. Electroanal. Chem., 1987, 222, 107-115.

27 S. Pons and M. Fleischmann, Anal. Chem., 1987, 59, A1391-A1399.

28 J. Heinze, Angew. Chem., Int. Ed. Engl., 1993, 32, 1268-1288. 29 K. Aoki, K. Honda, K. Tokuda and H. Matsuda, J. Electroanal. Chem., 1985, 182, 267-279.

30 K. Aoki, K. Honda, K. Tokuda and H. Matsuda, J. Electroanal. Chem., 1985, 186, 79-86.

31 K. Aoki, Electroanalysis, 1993, 5, 627-639.

32 M. Mehdizadeh, T. K. Ishii, J. S. Hyde and W. Froncisz, IEEE Trans. Microwave Theory Tech., 1983, 31, 1059-1064.

33 G. A. Rinard, R. W. Quine, S. S. Eaton and G. R. Eaton, J. Magn. Reson., Ser. A, 1993, 105, 137-144.

34 I. Dumitrescu, P. R. Unwin and J. V. Macpherson, Electrochem. Commun., 2009, 11, 2081-2084. 
35 M. Brustolon, Electron Paramagnetic Resonance, A practitioner's Toolkit, A John Wiley \& Sons, Inc., Hoboken, New Jersey, 2009.

36 G. Rinard and G. Eaton, in Biomedical EPR, Part B: Methodology, Instrumentation, and Dynamics, ed. S. Eaton, G. Eaton and L. Berliner, Springer US, 2005, vol. 24/B, pp. 19-52.

37 L. Zhuang and J. Lu, Rev. Sci. Instrum., 2000, 71, 4242-4248.

38 R. M. Elofson and R. L. Edsberg, Can. J. Chem., 1957, 35, 646-650.
39 C. L. Bird and A. T. Kuhn, Chem. Soc. Rev., 1981, 10, 49-82. 40 W. R. Dunham, J. A. Fee, L. J. Harding and H. J. Grande, J. Magn. Reson., 1980, 40, 351-359.

41 E. M. Kosower and J. L. Cotter, J. Am. Chem. Soc., 1964, 86, 5524-5527.

42 P. M. S. Monk, R. D. Fairweather, M. D. Ingram and J. A. Duffy, J. Chem. Soc., Perkin Trans. 2, 1992, 2039-2041.

43 C. Amatore, M. F. Bento and M. I. Montenegro, Anal. Chem., 1995, 67, 2800-2811. 